MINI-SYMPOSIUM

\title{
SOXF: redox mediators of vascular smooth muscle cell growth
}

\author{
Z G Jin, B C Berk
}

Heart 2004;90:488-490. doi: 10.1136/hrt.2003.029371

O xidative stress and the production of intracellular reactive oxygen species (ROS), such as superoxide $\left(\mathrm{O}_{2}{ }^{-}\right)$, hydrogen peroxide $\left(\mathrm{H}_{2} \mathrm{O}_{2}\right)$, and hydroxyl radical $\left(\mathrm{OH}^{\circ}\right)$, have been implicated in the pathogenesis of cardiovascular disease, in part by promoting vascular smooth muscle proliferation. ${ }^{1-4}$ Within the vessel wall, ROS are generated by several mechanisms, including vascular $\mathrm{NAD}(\mathrm{P}) \mathrm{H}$ oxidases. ${ }^{56}$ ROS formation can be stimulated by mechanical stress, environmental factors, platelet derived growth factor (PDGF), angiotensin II (Ang II), and low density lipoproteins. ${ }^{7-9}$ Because many risk factors for coronary artery disease such as hyperlipidaemia, hypertension, diabetes, and smoking increase production of ROS, it has been suggested that changes in vessel redox state are a common pathway involved in the pathogenesis of atherosclerosis and vascular injury. ${ }^{16} 10$

Several key findings support the concept that ROS contribute to vascular diseases through effects on vascular smooth muscle cells (VSMC). Initial studies in our laboratory demonstrated that ROS stimulate cultured VSMC proliferation and activate intracellular kinases such as mitogen activated protein kinases (MAPK) which are associated with proto-oncogene expression and cell growth. ${ }^{4112}$ Furthermore, we observed that in the injured vessel wall there is increased ROS production. Antioxidants decrease neointimal VSMC proliferation and promote outward vessel remodelling in the pig coronary injury model. ${ }^{13}{ }^{14}$ We showed that many proteins kinases are involved in ROS mediated signalling and gene expression. ${ }^{4-18}$ Recently we have demonstrated the novel finding that ROS stimulated VSMC synthesise and secrete proteins which may activate intracellular events in an autocrine and paracrine fashion. ${ }^{19}{ }^{20}$ In this article, we describe these factors, termed SOXF, for Secreted OXidative stress induced Factors, which are potentially important mediators of the vessel wall response to ROS.

\section{PURIFICATION AND IDENTIFICATION OF SOXF}

ROS stimulate VSMC growth and DNA synthesis ${ }^{11}$ by activating signal cascades such as those involving the extracellular signal regulated kinases $(\mathrm{ERKl} / 2) .{ }^{4}$ We found that activation of ERKl/2 by $\mathrm{O}_{2}{ }^{-}$- generators such as the napthoquinolinedione LY83583, menadione, and xanthine/ xanthine oxidase was biphasic: an early peak of ERK1/2 activity was present at 5-10 minutes, whereas a delayed ERKI/2 activation appeared at two hours. ${ }^{21} \mathrm{~A}$ similar biphasic activation of ERKl/2 has been reported for mitogens such as fibroblast growth factor. ${ }^{22}$ One logical mechanism for endothelial cells and VSMC to respond to ROS would be to produce autocrine/paracrine signals that enhance cell survival or stimulate pathways that protect cells from the damaging effects of ROS. VSMC are particularly likely to secrete protective factors that also promote cell survival based on previous studies that demonstrate secretion of growth factors from VSMC in response to various stimuli. ${ }^{23}$
To identify the presence of SOXF from VSMC stimulated by LY83583, the ability of conditioned medium to stimulate ERKl/2 was assayed. ERKl/2 activity, measured with a phospho-ERKl/2 specific antibody, demonstrated a significant increase with conditioned medium from VSMC treated with LY83583, but not in control cells. The activity was sensitive to trypsin $(5 \mu \mathrm{g} / \mathrm{ml}$ for 30 minutes $)$, and was inhibited by heating to $100^{\circ} \mathrm{C}$, suggesting a protein factor or factors. We analysed the proteins released into the medium in response to LY83583, by $\left[{ }^{35}\right.$ S $]$ methionine labelling. Approximately 35 protein bands were detected by autoradiography, suggesting that multiple proteins were released in response to LY83583.

To purify SOXF we used a sequential chromatographic approach that involved SP-Sepharose, heparin-Sepharose, phenyl Sepharose, and S-200 gel filtration chromatography. ${ }^{19}$ For each step, activity was assayed for ERK1/2 stimulation by phospho-ERKl/2 Western blot using growth arrested VSMC. SOXF activity was associated with three protein peaks of approximate molecular weights $80-100 \mathrm{kD},>20-30 \mathrm{kD}$, and $>45-65 \mathrm{kD}$, respectively (in order of relative ERKl/2 stimulating activity). Proteins were identified by tryptic digestions followed by mass spectrometry. The collision induced dissociation spectra were used to identify the proteins from which the peptide originated by database searching using the Sequest software program. ${ }^{24} 25$ Unambiguous identification of proteins in the $90 \mathrm{kD}$ band revealed heat shock protein $90-\alpha$ (HSP90- $\alpha$ ). Unambiguous identification of proteins in the $20 \mathrm{kD}$ band revealed cyclophilin B (CyPB) and cyclophilin A (CyPA). No proteins were identified in the $56 \mathrm{kD}$ and $27 \mathrm{kD}$ bands. Other proteins identified included ezrin and moesin.

To prove that proteins identified as putative SOXF were released specifically from LY83583 treated VSMC, we compared the relative protein abundance of candidate SOXF proteins in the total cell lysate and in conditioned medium, before and after LY83583 stimulation. Conditioned media from control and LY83583 treated cells were concentrated, then analysed by SDS-PAGE followed by Western blot analysis for HSP90 (with an antibody that recognises both HSP90- $\alpha$ and HSP90- $\beta$ ). The abundance of HSP90 was compared to two intracellular proteins of similar molecular weights; PKC- $\xi$ (with an antibody which also recognizes PKC- $\alpha$ ), and c-Raf- 1 . After treatment with LY83583 for two hour, there was a 10-fold increase in HSP90- $\alpha$ present in the conditioned medium, but no detectable HSP90- $\beta$, PKC or cRaf-1. These results suggest that regulated secretion of HSP90- $\alpha$ occurred in response to LY83583.

\footnotetext{
Abbreviations: Ang II, angiotensin II; CyPA, cyclophilin A; ERK, extracellular regulated signal kinase; HSP9O, heat shock protein 90; PDGF, platelet derived growth factor; PPlase, peptidyl-prolyl cis-trans isomerase; ROS, reactive oxygen species; SOXF, secreted oxidative stress induced factors; VSMC, vascular smooth muscle cells
} 
To study the role of intracellular ROS in CyPA function, we studied cells transfected with noxl (homolog of the NADPH oxidase catalytic subunit) to stimulate ROS production. ${ }^{26}$ CyPA expression and secretion were increased, and antioxidants blocked the secretion of CyPA from noxl-transfected cells. ${ }^{20}$

\section{FUNCTIONAL STUDIES OF SOXF}

To provide further evidence that HSP90- $\alpha$ and CyPA are SOXF, human recombinant HSP90- $\alpha$ (hrHSP90- $\alpha$ ) and hrCyPA were purified and tested on VSMC cultures. Both CyPA and hrHSP90- $\alpha$ stimulated ERKl/2 activity in VSMC in a concentration dependent manner. ${ }^{19} 20$

To determine the physiological significance of SOXF, we studied the effects of hrCyPA on VSMC DNA synthesis: $10 \mathrm{nmol} / \mathrm{l}$ hrCyPA significantly stimulated DNA synthesis in VSMC (twofold increase versus $0.1 \%$ serum) assayed by $\left[{ }^{3} \mathrm{H}\right]$ thymidine incorporation. ${ }^{20}$ Thus, CyPA has growth promoting effects on VSMC which may contribute significantly to the growth promoting activity of ROS in VSMC. To further determine whether CyPA prevents VSMC apoptosis, we used sodium nitroprusside (SNP), which was shown to induce VSMC apoptosis. ${ }^{27}{ }^{28}$ Incubating VSMC with $1 \mathrm{mmol} / \mathrm{l}$ SNP for 24 hours decreased cell viability to $19.4 \%$ of control, measured with a modified MTT assay. Addition of $10 \mathrm{nM}$ hrCyPA in the presence of $1 \mathrm{mmol} / \mathrm{l}$ SNP blocked apoptosis, with cell viability returning to $47 \%$ of control. ${ }^{20}$ In response to $0.5 \mathrm{mmol} / \mathrm{l} \mathrm{SNP}$ for 24 hours, $10 \%$ of VSMC were apoptotic as measured by nuclear morphology after DAPI staining, consistent with previous reports. ${ }^{27}{ }^{28}$ Addition of hrCyPA significantly inhibited apoptosis induced by $0.5 \mathrm{mmol} / \mathrm{l} \mathrm{SNP}$ with a decrease of 55\%. These results indicated that SOXF have significant physiological effects on VSMC.

To study whether SOXF are involved in vascular lesion formation in vivo, we examined the expression of CyPA in balloon injured rat carotid arteries, ${ }^{20}$ since this model is associated with ROS generation, and neointima formation in injured vessels develops largely as a consequence of VSMC proliferation. ${ }^{29}{ }^{30}$ Morphologic analysis demonstrated formation of a neointima within a week after injury. Immunoreactive CyPA was present at low level in sections of sham operated arteries. By 24 hours after balloon injury, abundant CyPA immunoreactivity was present throughout the vessel with particularly strong staining in the adventitia. By day 4, the majority of the CyPA staining was localised to the first cells forming the neointima and the most luminal medial VSMC layers. After one week of injury, when a substantial neointima had formed, CyPA immunoreactivity was highest in the neointima and most luminal medial VSMC. These findings show that CyPA expression is dramatically increased with a time course that paralleled neointima formation, suggesting an important role for CyPA in the cell response to oxidative stress induced by vascular injury.

\section{CONCLUSION}

In summary, our recent studies demonstrate that CyPA and HSP90 are secreted redox sensitive mediators. Because both cyclophilins and heat shock proteins act as chaperones, their secretion suggests an important role in the stress response to ROS in maintaining normal protein folding and function. The novel findings of our work suggest roles for HSP90 and CyPA as mediators themselves by promoting cell survival and growth. Understanding the mechanisms by which ROS stimulate gene expression and protein secretion should provide important insights into the cellular response to oxidative stress and new therapeutic targets for cardiovascular disease.

\section{ACKNOWLEDGMENTS}

This work was supported by grants from National Institutes of Health (HL4472 1 and HL49192 to BCB) and from American Heart Association (0235480T to ZJ).

\section{Authors' affiliations}

Z G Jin, B C Berk, Center for Cardiovascular Research, University of Rochester, New York, USA

Correspondence to: Bradford C Berk, MD, PhD, University of Rochester, Department of Medicine, Box MED, Rochester, NY 14642, USA;

bradford_berk@urmc.rochester.edu

\section{REFERENCES}

1 Alexander RW. Theodore Cooper Memorial Lecture. Hypertension and the pathogenesis of atherosclerosis. Oxidative stress and the mediation of arterial inflammatory response: a new perspective Hypertension 1995;25:155-61

2 Abe J, Berk BC. Reactive oxygen species as mediators of signal transduction in cardiovascular disease. Trends Cardiovasc Med 1998:8:59-64.

3 Omar HA, Cherry PD, Mortelliti MP, et al. Inhibition of coronary artery superoxide dismutase attenuates endothelium-dependent and -independent nitrovasodilator relaxation. Circ Res 1991;69:601-8.

4 Baas AS, Berk BC. Differential activation of mitogen-activated protein kinases by $\mathrm{H} 2 \mathrm{O} 2$ and $\mathrm{O} 2$ - in vascular smooth muscle cells. Circ Res 1995;77:29-36.

5 Mohazzab KM, Kaminski PM, Wolin MS. NADH oxidoreductase is a major source of superoxide anion in bovine coronary artery endothelium. Am J Physiol 1994;266:H2568-72.

6 Rajagopalan S, Kurz S, Munzel T, et al. Angiotensin II-mediated hypertension in the rat increases vascular superoxide production via membrane NADH/ NADPH oxidase activation. Contribution to alterations of vasomotor tone. J Clin Invest 1996;97:1916-23.

7 Wung BS, Cheng JJ, Hsieh HJ, et al. Cyclic strain-induced monocyte chemotactic protein-1 gene expression in endothelial cells involves reactive oxygen species activation of activator protein 1. Circ Res 1997;81:1-7

8 Sundaresan $M, Y u$ ZX, Ferrans VJ, et al. Requirement for generation of $\mathrm{H}_{2} \mathrm{O}_{2}$ for platelet-derived growth factor signal transduction. Science 1995;270:296-9.

9 Griendling KK, Minieri CA, Ollerenshaw JD, et al. Angiotensin II stimulates NADH and NADPH oxidase activation in cultured vascular smooth muscle cells. Circ Res 1994;74:1141-8.

10 Halliwell B. Free radicals, reactive oxygen species and human disease: a critical evaluation with special reference to atherosclerosis. Br J Exp Pathol 1989;70:737-57.

11 Rao GN, Berk BC. Active oxygen species stimulate vascular smooth muscle cell growth and proto-oncogene expression. Circ Res 1992;70:593-9.

12 Rao GN, Lassegue B, Griendling KK, et al. Hydrogen peroxide-induced c-fos expression is mediated by arachidonic acid release: role of protein kinase $C$. Nucl Acids Res 1993:21:1259-63.

13 Nunes GL, Sgoutas DS, Redden RA, et al. Combination of vitamins C and E alters the response to coronary balloon injury in the pig. Arterioscler Thromb Vasc Biol 1995; 15:156-65.

14 Nunes GL, Robinson K, Kalynych $A$, et al. Vitamins $\mathrm{C}$ and $\mathrm{E}$ inhibit $\mathrm{O}_{2}$ production in the pig coronary artery. Circulation 1997;96:3593-601.

15 Abe J, Kusuhara M, J. UR, et al. The role of big MAP kinase 1 (BMK1) as a redox sensitive kinase in vascular smooth muscle cells (abstract). Circulation 1996; $94: 1-280$.

16 Abe J, Berk BC. Fyn and JAK2 mediate Ras activation by reactive oxygen species. J Biol Chem 1999;274:21003-10.

17 Abe J, Okuda M, Huang Q, et al. Reactive oxygen species activate p90 ribosomal S6 kinase via fyn and ras. J Biol Chem 2000;275:1739-48.

18 Yoshizumi M, Abe J, Haendeler J, et al. Src and cas mediate JNK activation but not ERK $1 / 2$ and $\mathrm{p} 38$ kinases by reactive oxygen species. J Biol Chem 2000;275:11706-12.

19 Liao D-F, Jin Z-G, Baas AS, et al. Purification and identification of secreted oxidative stress-induced factors from vascular smooth muscle cells. J Biol Chem 2000;275:189-96.

20 Jin ZG, Melaragno MG, Liao DF, et al. Cyclophilin A is a secreted growth factor induced by oxidative stress. Circ Res 2000;87:789-96.

21 Liao D-F, Baas AS, Daum G, et al. Purification of a secreted protein factor induced by reactive oxygen species (ROS) in vascular smooth muscle cells (VSMC). Circulation 1997:96:1-901.

22 Meloche S, Seuwen K, Pages G, et al. Biphasic and synergistic activation of p44 ${ }^{\text {mapk }}$ (ERK1) by growth factors: correlation between late phase activation and mitogenicity. Mol Endocrinol 1992;6:845-54.

23 Berk BC. Vascular smooth muscle growth: autocrine growth mechanisms. Physiol Rev 2001;81:999-1030.

24 Yates III JR, Eng JK, McCormack AL, et al. Method to correlate tandem mass spectra of modified peptides to amino acid sequences in the protein database. Anal Chem 1995;67:1426-36. 
25 Figeys D, Ducret A, Yates JR, et al. Protein identification by solid phase microextraction-capillary zone electrophoresis-microspray-tandem mass spectrometry. Nature Biotechnol 1996;14:1579-83.

26 Suh YA, Arnold RS, Lassegue B, et al. Cell transformation by the superoxidegenerating oxidase Mox1. Nature 1999:401:79-82.

27 Pollman MJ, Yamada T, Horiuchi M, et al. Vasoactive substances regulate vascular smooth muscle cell apoptosis. Countervailing influences of nitric oxide and angiotensin II. Circ Res 1996;79:748-56.
28 Zhao Z, Francis CE, Welch G, et al. Reduced glutathione prevents nitric oxideinduced apoptosis in vascular smooth muscle cells. Biochim Biophys Acta 1997; 1359:143-52.

29 Gong KW, Zhu GY, Wang LH, et al. Effect of active oxygen species on intimal proliferation in rat aorta after arterial injury. J Vasc Res 1996;33:42-6

30 Clowes AW, Reidy MA, Clowes MM. Mechanisms of stenosis after arterial injury. Lab Invest 1983;49:208-15.

\section{IMAGES IN CARDIOLOGY}

\section{Polytetrafluoroethylene (PTFE) covered stents for the treatment of coronary artery aneurysms}

oronary artery aneurysms are rare disorders defined by a vessel diameter $>1.5$ times the reference artery. Aneurysms can be characterised by abnormal dilatation of a localised or diffuse arterial segment. Potential complications associated with these abnormalities include thrombus formation and distal embolisation and, rarely, rupture. Until recently, the only alternative to medical treatment was surgical ligation of the aneurysm with distal bypass surgery. We report on the effectiveness of polytetrafluoroethylene (PTFE) covered stents in the treatment of two separate patients. In both cases the aneurysms were most likely caused by coronary artery atherosclerosis.
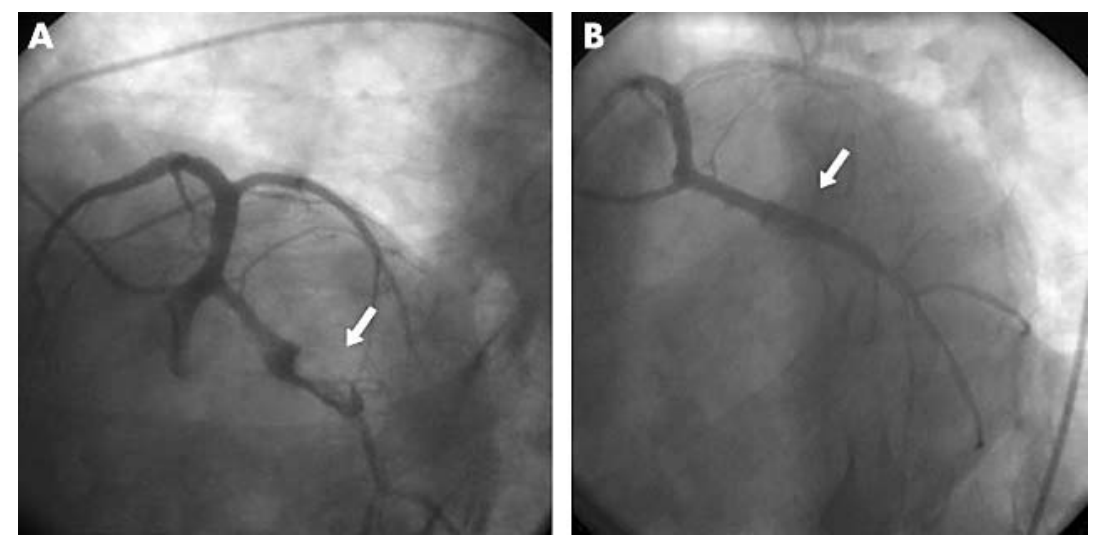

M Fineschi

T Gori

G Sinicropi

A Bravi

orfine@tin.it

(A) 71 year old male, admitted for angina at rest. History of previous non- $Q$ wave myocardial infarction. Coronary angiography showed a thrombus containing giant aneurysm of the left circumflex coronary artery as well as a $>75 \%$ stenosis distal to the aneurysm. (B) Two PTFE covered stents $(4.0 \times 19 \mathrm{~mm}+4.0 \times 16 \mathrm{~mm}$, GraftMaster Jostent, Jomed) were necessary to cover this large fusiform aneurysm completely. High pressure balloon post-dilatation was performed with final TIMI 3 grade flow. The patient was pre-treated with glycoprotein Illb/llla inhibitors. Upon discharge, clopidogrel and aspirin treatment was started. The patient was well at three months follow up.
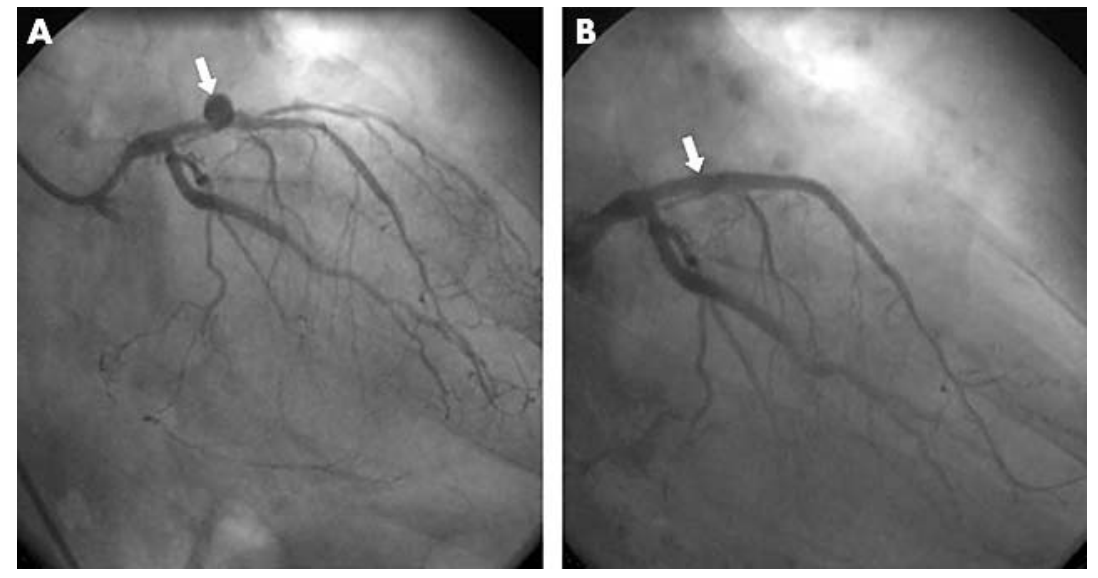

(A) 77 year old male, admitted for unstable angina. Coronary angiography revealed triple vessel coronary artery disease and a large saccular aneurysm of the proximal left anterior descending coronary artery. A $75 \%$ stenosis was present in the artery immediately proximal to the aneurysm. (B) Both stenosis and aneurysm were treated with a PTFE covered stent $(3.0 \times 16 \mathrm{~mm}$, GraftMaster Jostent, Jomed). The covered stent completely closed the entrance of the aneurysm, and no contrast medium was seen entering the aneurysm in the final angiographic images. The first diagonal branch was occluded, causing a lateral myocardial infarction with creatine phosphokinase peak of $891 \mathrm{IU} / \mathrm{I}$. The patient was discharged after six days, and treatment with aspirin and clopidogrel was begun. 